\title{
CASE STUDY: ATTITUDES OF ELTE STUDENTS TOWARD SPORTS DURING THE 2020 COVID-19 PANDEMIC
}

Katalin Kovacs, Ágnes Huszár, Ágnes Novák, Eötvös Lorand University Faculty of

Education and Psychology Institute of Health Promotion and Sport Sciences, Hungary

\begin{abstract}
In the spring of 2020 during the coronavirus pandemic, teaching of physical education at Eötvös Loránd University continued in the virtual space. Physical education teachers conducted an online training program weekly for students. It was a significant challenge for teachers to change the curricula overnight to support students' physical activity needs and to motivate them as required. In our study we examined the effectiveness of the 7-week online physical education program based on feedback from 264 non- athletically competitive university students. This virtual experience provided instructive results, which support the introduction of blended physical education in higher education.
\end{abstract}

Keywords: COVID-19, virtual physical education, higher education, physically active lifestyle

\section{Introduction}

At Eötvös Loránd University in Budapest, physical education is an optional course for students every semester. The University offers some 25-30 different courses, including outdoor (hiking, skiing, cycling, etc.), indoor (sport games, conditioning, dancing, etc.) and aquatics sports. The students participate in 60-90 minute lessons (depending on the course) weekly led by physical education teachers. The conditions for awarding credits hours are determined by the teachers.

At the beginning of the COVID-19 pandemic on March 15, 2020, the University offered students the opportunity to complete these courses online or drop them without consequences. In the 2019/20 academic year, almost 900 students signed up for these P.E. courses and 687 continued through the end of the semester with the distance learning component. 
Physical educators at the university faced a serious challenge, as in previous years classes were held $100 \%$ face-to-face. The university's e-learning platform had primarily been used as a communication interface rather than an educational tool. Furthermore, domestic articles were entirely unavailable, and there was limited guidance from international studies (Daum \& Buschne, 2012; 2014; Williams, 2013) which primarily presented experiences from fitness courses.

\section{Aims}

During the rapid shift, the following educational goals were set for the 7-week online physical education courses:

- Maintain general fitness levels;

- Self-regulated implementation of a physically active and healthy lifestyle with virtual assistance.

\section{Methodology}

The programs were conducted through the university's online system, where teachers uploaded movement programs. Students were provided a suitable warm-up for each program and a stretching program for the end of the session. The duration of the online course was 7 weeks, and students could choose from the following programs: Conditioning, aerobics, posture improvement, dynamic yoga, hiking/running, cycling and healthy lifestyle (as a theoretical course.) Students were free to choose a new program weekly, or stay with one program throughout the 7 week period and monitor their progress. Moreover, they could participate in multiple programs per week according to their attitude and time. Students were required to send feedback on a weekly basis based on the criteria given. The reports had the following dual purpose:

68. To provide information and feed-back for teachers on whether is it necessary to modify the virtual curriculum;

69. To provide for self-reflection by the students in which their movements and results (e.g. Strava, heart rates, calories, etc.) were recorded and evaluated.

The virtual content was provided in various media, including descriptions, drawings, and demonstrations videos.

\section{Questions}

The purposes of the study were as follows:

- To analyse the extent to which distance learning can maintain regular physical activity in students, and determine whether the differences between individual and team sport athletes. 
- To evaluate the extent to which the 7-week distance learning succeed in transferring the theoretical and practical foundations of a physically active lifestyle to university students. It was assumed that by the end of the course they would be able to develop theirown exercise program according to their own needs.

\section{Study Group}

The online questionnaire was completed by a total of 384 students in the final days of the semester from May 1124, 2020.

Table 1: $\quad$ Study group

\begin{tabular}{|c|c|c|c|c|c|c|c|}
\hline & \multicolumn{2}{|c|}{ Competitive athletes } & \multicolumn{2}{|c|}{ Recreational athletes } & \multicolumn{2}{|c|}{ Not active } & \multirow[t]{2}{*}{ Total } \\
\hline & Female & Male & Female & Male & Female & Male & \\
\hline Team sports & 14 & 20 & 25 & 15 & \multirow{2}{*}{ N.A. } & \multirow{2}{*}{ N.A. } & 74 \\
\hline Individual sports & 4 & 6 & 157 & 67 & & & 234 \\
\hline & 18 & 26 & 182 & 82 & 53 & 23 & 76 \\
\hline Total & \multicolumn{2}{|c|}{44} & \multicolumn{2}{|c|}{264} & \multicolumn{2}{|c|}{76} & 384 \\
\hline
\end{tabular}

In the study the 264 students were examined who regularly practiced sports at a recreational level, in addition to the university P.E. class, before the pandemic. The sample consisted of BSc, MSc and Ph.D. students born in 1979-2001. The distribution of residence is described in Table 2.

Table 2: $\quad$ Type of sport that was practiced by place of residence.

\begin{tabular}{lccccc}
\hline & Capital & Small town & County seat & City & Total \\
\hline Team sports & 12 & 6 & 5 & 17 & 40 \\
Individual sports & 88 & 34 & 37 & 65 & 224 \\
\hline Total & 100 & 40 & 42 & 82 & 264 \\
\hline
\end{tabular}

\section{Results}

During the restrictions, $42 \%$ of students continued to exercise regularly in addition to the online courses. While $35 \%$ of team athletes continued to exercise, this increased to $43 \%$ of the individual sport athletes.

However, a closer look at the results (Table 3) shows that among the team athletes a large proportion ceased training in the capital, while among those students living in cities only 1 person stopped training regularly. In individual sports, a high proportion of students living in county seats and cities stopped training (69\% and $62 \%$ respectively), while only half of those resident in the capital and small settlements gave up regular exercise. 
Kovacs, K., Huszár, Á., \& Novák, Á.

Case Study: Attitudes of ELTE Students toward Sports during the 2020 Covid-19 Pandemic

Table 3: Did you exercise during the COVID restrictions? (by place of residence)

\begin{tabular}{lccc}
\hline & Yes & No & Total \\
\hline CAPITAL & 45 & 55 & 100 \\
\hline team sports & 2 & 10 & 12 \\
individual sports & 43 & 45 & 88 \\
\hline COUNTY SEAT & 13 & 29 & 42 \\
\hline team sports & 1 & 4 & 5 \\
Individual sports & 12 & 25 & 37 \\
\hline CITY & 34 & 48 & 82 \\
\hline team sports & 9 & 8 & 17 \\
individual sports & 25 & 40 & 65 \\
\hline SMALL TOWN & 19 & 21 & 40 \\
\hline team sports & 2 & 4 & 6 \\
individual sports & 17 & 17 & 34 \\
\hline Total & 111 & 153 & 264 \\
\hline
\end{tabular}

Prior to the restrictions, $34 \%$ of students spent less than 3 hours per week on physical activity and 46\% spent 3-6 hours. The rest of the students spent trained for over 6 hours per week. (Table 4)

Table 4: How much time was spent with physical activity per week before the restrictions?

\begin{tabular}{lccccc}
\hline & More than 10 hours & $7-10$ hours & $3-6$ hours & Less than 3 hours & Total \\
\hline Team sports & 3 & 10 & 18 & 9 & 40 \\
Individual sports & 6 & 32 & 104 & 82 & 224 \\
\hline Total & 9 & 42 & 122 & 91 & 264 \\
\hline
\end{tabular}

Of the students who barely exercised before the pandemic, $48 \%$ increased their weekly workout hours; while 14\% have reported no change. For those who exercised 3-6 hours or 7 and more hours weekly before the restrictions this favourable change was not observed. (Table 5)

Table 5: How weekly activity developed during the restrictions

\begin{tabular}{lccccc}
\hline & More than 10 hours & $7-10$ hours & $3-6$ hours & Less than 3 hours & Total \\
\hline Significantly decreased & 2 & 14 & 33 & 27 & 76 \\
team sports & 0 & 6 & 7 & 2 & 15 \\
individual sports & 2 & 8 & 26 & 25 & 61 \\
barely decreased & 4 & 8 & 36 & 7 & 55 \\
team sports & 1 & 2 & 6 & & 9 \\
individual sports & 3 & 6 & 30 & 7 & 47 \\
same amount & 2 & 8 & 18 & 13 & 43 \\
team sports & 1 & 1 & 2 & 4 & 9 \\
individual sports & 1 & 7 & 16 & 9 & 34 \\
increased & 1 & 12 & 35 & 44 & 92 \\
team sports & 1 & 1 & 3 & 3 & 8 \\
individual sports & & 11 & 32 & 41 & 84 \\
\hline Total & 9 & 42 & 122 & 91 & 264 \\
\hline
\end{tabular}


Based on the above, it appears that the virtual physical education program partially maintained student mobility. Motivation was more successful among students engaged in individual sports; however, the place of residence and previous training regime also appears to impact the results.

The second part of the questionnaire investigated the extent distance learning can influence students' quality of life through movement.

In the questionnaire, 74 students responded that they had pains during the pandemic that they had not experienced before. It is likely that the sudden onset of sedentary life and the significantly increased hours in front of the computer caused these problems. Of these students, $66 \%$ were able to relieve or eliminate their pain with exercise. Individual and team athletes were similarly successful (Table 6).

Table 6: Did exercise reduce pain?

\begin{tabular}{lccc}
\hline & Team sports & Individual sports & Total \\
\hline Yes & 8 & 41 & 49 \\
No & 4 & 21 & 25 \\
\hline Total & 12 & 62 & 74 \\
\hline
\end{tabular}

By the end of the 7-week course, 226 students reported that they could create an exercise program based on their own requirements. (Table 7) Most selected a series of conditional exercises and 131 students (including 17 team players) stated that they also knew the danger of injury of the program they had put together.

Table 7: Could you put together an exercise program to suit your own needs?

\begin{tabular}{llll}
\hline & Team sports & Individual sports & Total \\
\hline Yes & 34 & 192 & 226 \\
No & 7 & 34 & 41 \\
\hline Grand total & 41 & 226 & 267 \\
\hline
\end{tabular}

While only a small number of students reported negative signs of a sedentary lifestyle, the study period was barely two months and the participants were young people in their twenties. More importantly, by the end of the online course students who previously led an active lifestyle were able to put together an exercise program that helped maintain physical and mental balance. Unfortunately, barely half of them were aware of the potential for injury and other movement related hazards.

\section{Summary}

Overall, the study suggests that distance learning in physical education can be useful for students in higher education, including participants in both team sports players and individual athletes. The study showed that individual athletes are more open to virtual training, which can be traced back to the feasibility of adapting existing practices to the 
lock-down environment among other things. Based on the feedback, students exercised more hours than during the face-to-face course, as the programs were always available and the number of repetitions was not limited. True, the majority of respondents stated that their biggest concern was the lack of immediate feedback and community.

\section{Recommendation}

Whether we are talking about online or face-to-face education in the future, it is important to consider that

In order to better differentiate the students at the start of the course, a short questionnaire should be given not only on sporting experience and future expectations, but also on movement habits (e.g. weekly regularity, timing during the day, etc.) and circumstances (e.g. individual or group, outdoor or indoor, etc.)

For university students, where one of the main tasks of physical education classes is to develop a physically active lifestyle, hybrid education can actually increase effectiveness. The blended method provides the following benefits:

- During face-to-face teaching sessions, teachers focus on proper body position and accurate movement execution.

- During independent training sessions, students develop a regular active lifestyle with guidance but without supervision.

In the future, we must consider the opportunities and challenges of blended learning, to the benefit or our students who will be more physically active and have a healthier life after the graduation, too.

\section{References}

Daum, D. N., \& Buschner, C. (2012). The Status of High School Online Physical

Education in the United States. Journal of Teaching in Physical Education, 31(1), 86100. Retrieved from https://journals.humankinetics.com/view/journals/jtpe/31/1/article-p86.xml

Daum, D. N., \& Buschner, C. (2014). Research on Teaching Blended and Online Physical Education. In R. E. Ferdig, \& K. Kennedy (Eds.), Handbook of Research on K-12 Online and Blended Learning ( $1^{\text {st }}$ ed., Chapter 9, pp. 201-221). Pittsburgh, PA: Carnegie Mellon University, ETC Press.

Williams, L. M. (2013). A Case Study of Virtual Physical Education Teachers' Experiences in and Perspectives of Online Teaching. Graduate Thesis and Dissertations. University of Southern California. Retrieved from https://scholarcommons.usf.edu/cgi/viewcontent.cgi?article $=6158 \&$ context $=$ etd 